\title{
"The Poetics of Dissolution: The Representation of Maori Culture in Janet Frame's Fiction"
}

\author{
Cindy Gabrielle (University of Liege, Belgium)
}

\begin{abstract}
This essay examines Janet Frame's early short story "The Lagoon", and argues that the story alludes to Maori experience, albeit tangentially, in a way which anticipates similar evocations in novels such as A State of Siege and The Carpathians. A close reading shows that cultural imperialism in Frame runs parallel to, or is a side-effect of, interpersonal appropriations. These, in turn, seem to be rooted in human beings' reluctance to accommodate otherness. Recurrently Janet Frame points to a model of cultural and interpersonal interaction which is detached from proprietorial forms of appropriation, but which entails nothing less than the dissolution of the ruling ego. Self-dissolution shall emerge in this reading as the key to a utopian state consisting of the total permeability between the self and the remainder of the world. In this state, transactions become reciprocal since the divisions between self and nonself no longer exist.
\end{abstract}

\section{Keywords:}

Janet Frame; self-dissolution; the Maori; cultural and metaphorical appropriations; accommodating otherness

Janet Frame's story "The Lagoon", also the title of her first published volume, obliquely alludes to the devious desire on the part of Pakeha New Zealanders to appropriate a sense of Maori life experience. She would return to this topic with even greater satirical force in $A$ State of Siege and The Carpathians. Together with the longer texts, the short story notably yields to a postcolonial interpretation but it also seems to me of special interest in that it foregrounds an unprecedented attempt on the author's part to delineate her stance towards the indigenous population in New Zealand. Although the issue of Janet Frame's postcoloniality has become an important focus in contemporary criticism, few have, to my knowledge, examined it in the light of the author's hankering for "a way of being in the world that inheres in the confrontation and collapse of the boundaries between seeming oppositional terms" 
(Michell 123). One thinks, notably, of the differentiation between self and world which, if it were transcended, would alleviate feelings of estrangement from nature. In settler colonies, such closeness to nature tends to be associated with the indigenous populations, "recognized [...] as having greater roots in the place" (Goldie 14). In integrating extraneous elements into their self-construction, settler colonies ostensibly skirt a "philosophical impasse" whereby the enmeshing of two cultures is denied by virtue of "the myth of group 'purity'" (Ashcroft, Griffiths, and Tiffin 35). In The Empire Writes Back, essentialist claims about identity are clearly condemned for their failure to deconstruct the binary oppositions informing the western philosophical tradition, which they simply invert, thereby perpetuating legacies of conquest and annihilation. The permeability of cultures which The Empire Writes Back vindicates, however, becomes highly problematical when approached in the specific context of settler colonies. Terry Goldie demonstrates in his groundbreaking study Fear and Temptation that the dominant culture's yearning to incorporate indigenous features into its identity construction is in essence a neo-colonial endeavour as it amounts to an attempt to appropriate the place occupied by the indigene. Far from dismantling any boundaries, the "indigenization" (13) of the white settler reinforces divisions between cultures.

To return to Frame, whilst Mark Williams argues convincingly that the author dismisses "the widespread desire for [...] identification with Maori legend" as essentially "self-deluding and self-interesting" (39), it is nevertheless the case that the individual who seeks to attain her utopian way of being in the world must necessarily be promoted to a rank similar to that occupied by the indigene. The point, however, is that manifold modes of appropriation exist in the Framean texts: some pertain to the cultural whereas others work on an interpersonal level; some reinstate or reinforce divisions whereas others (the utopian ones) collapse them and bring home the possibility of a true cross-cultural or cross-personal exchange. I wish to suggest that cultural imperialism in Frame runs parallel to, or is a sideeffect of, interpersonal appropriations which, in turn, seem to be rooted in human beings' distrust of permeability, in their reluctance to open up to the other; as Simone Drichel asserts, "ontological imperialism" is essentially a "freedom from otherness" (196). To set up a model of interaction that relies on a utopian form of appropriation, which may rather be termed "exchange", it is therefore necessary to conflate the cultural with the personal. Indeed, the notion of appropriation has assumed multiple guises throughout Frame's career. Often it materializes in human beings' impulse to seize and destroy, in their greed to cannibalize the essence of others of their kind, or, perhaps more evidently, in their keenness to stake unlikely claims. In "A Relative of the Famous", for instance, a "rich woman of esteem" (Reservoir 
143) longs to encourage Wilfred, an artistic individual, not for the sake of art but "to possess him, to stake her claim in his life" (147). The snowman in "Snowman, Snowman" for his part is puzzled by the realization that, "not knowing where to stop, [the human ego] devours friends and enemies" (Human Heart 11). The self in fact is such a voracious creature that it seeks, without cease, to tap into other people's secret thoughts, their successes and desires, their point of view or memories, so much so that the narrator in "Prizes" exclaims: "See how derivative I was made out to be? Nothing belonged to me, not even my body" (Reservoir 26).

The notion of appropriation also suffuses Frame's longer texts. Istina Mavet in Faces in the Water ponders the nurses' attempts to "move into [her] 'changed' personality like immigrants to a new land staking their claims" (191) and regrets that "much of living is an attempt to preserve oneself by annexing and occupying others" (193). A prime component in The Edge of the Alphabet is "Toby's suspicion that everyone around him is about to poach the idea of the Lost Tribe" (Jennings 85). A further example is undoubtedly the glorification, in $A$ State of Siege, of dead Mr. Signal's memory, which, however, does little justice to the man's humility. This, in turn, prompts his daughter Malfred to understand that memories can be "seized, held to the light, snipped, trimmed, polished, gilded [and] reshaped" (180). Malfred observes a similar attempt at "trimming" the past in New Zealanders' growing desire to "stake a claim in the identity of their country" (124) by identifying with Maori religious beliefs. That "seizing and reshaping" or "staking claims" pertains to cultural as well as to other appropriations is of crucial importance for the forthcoming discussion.

Inevitably, perhaps, Frame's suggestion in these above examples that anyone can be either the victim or the perpetrator of ruthless dispossession runs the risk of being interpreted as an attempt to absolve the Pakeha of their colonizing urges in appropriating indigeneity. Yet this universality is the key to understanding how the impulse to appropriate can be eliminated from human nature. The solution Janet Frame advocates is no less than the dissolution of selves. In Manifold Utopia, Marc Delrez evokes the fluidity of identities in Frame's work and points to a "universal dimension of being" (101) as pertaining to her utopia. This, in fact, illuminates a major existential tension in Frame's work between human beings' true nature and their insistence that identity is self-contained and resists interpenetration with other beings. To Frame, the separation between one human being and another is as spurious as that between races, yet the consequences of such denial are no less tangible than the effects of racial discrimination. In keeping with his view that "bodily decrepitude" and "physical disintegration" (Delrez, "Forbidding Bodies" 70) is the most expeditious way of reconnecting with one's true nature (since death is the ultimate state of dissolution), Delrez posits death as 
the "moment of accession to a form of collective being" (73). For my part, I wish to contend that another kind of dissolution exists in the Framean texts, one which works on a spiritual level and is not necessarily lethal. What I call self-dissolution is less a natural physical state than the suspension of one's disbelief in the fluidity of identities. As Delrez intuits, however, to truly reach a state of ontological permeability, the individual must die to him- or herself, for identity in its usual configuration is a thick membrane that allows no reciprocal transactions between the self and the outside world or other selves. Self-dissolution, therefore, must be construed as the sacrifice, prior to death, of the ego in favour of a long-deferred communion with the world, whereby transactions between one individual and the next indeed become reciprocal since the divisions between self and non-self no longer exist and the ego, which excludes and appropriates, has been dismantled. Frame's particular brand of spiritual dissolution, which allows one to know and be known by neutralizing the destructive potential of appropriation, is already present, albeit in very embryonic form, in "The Lagoon". This short story is a seminal text, perhaps a blueprint for A State of Siege and The Carpathians, and shall therefore be examined minutely in what follows and used to delineate a general interpretive pattern, which shall be tested against the larger evidence provided by these longer texts.

"The Lagoon" is an ostensibly simple five-page story which recounts a young woman's impressions of the town of Picton and its lagoon, a place with which she used to be familiar from childhood visits and which she discovers anew when travelling there as an adult. As she embarks on an exploration of "the new Picton" (Frame, The Lagoon 5), it occurs to her that:

If there were things I hadn't noticed before there were also things gone that I thought would be there for ever. The two gum trees that I called the two ladies were gone, or if they were there I couldn't find them [...]. And there was gorse mixed up with the bush and the bush itself didn't hold the same fear, even with its secret terrible drippings and rustlings that go on for ever. (5)

The young adult is surprised by the extent to which the town and the surrounding hills now appear to be diminished in size and resents the inadequacy of memory for recalling the past and helping familiarize her with an environment which seems to have shrunk out of all proportion. Her disorientation is increased by the absence of her grandmother with whom she used to explore the place. She misses the stories the grandmother would tell "about the Maori 
Pa. About the old man who lived down the Sounds and had a goat and cow for friends" (4). Sadly, the complicity which existed between the matriarch and her granddaughter, together with the kind of knowledge transmitted from mentor to child, pertain to a past which is irremediably lost, for the grandmother has died and "most of the old Maoris were gone from the $\mathrm{Pa}$, and the old man and the cow and the goat were forgotten" (4).

Interestingly, it is an aspect of this complete sense of loss, or of the natural attrition which characterizes human experience, that the narrator must do without the kind of connection with the Maori that earlier generations of the family used to enjoy. As she admits, "When my grandmother died all the Maoris at the Pa came to her funeral, for she was a friend of the Maoris, and her mother had been a Maori princess, very beautiful, they said, with fierce ways of loving and hating" (1-2). This reflects part of the narrator's actual genealogy, and suggests that she has a personal stake in a Maori heritage which has become diluted within the family and occulted from contemporary consciousness. Now it can no longer be dissociated from a secret running in the family, which the narrator would like to uncover. As we shall see, such an investigation would imply a gradual recovery of lost objects that finds an objective correlative in the lagoon itself, which in its ebbing and flowing reveals all kinds of secret treasures left behind.

Whether the narrator, like her grandmother, is able to "cut supple-jack and find kidney fern and make a track through the thickest part of the bush" (3) is also not made explicit in the text. What is clear, however, is that the exodus of the Maori from their $\mathrm{Pa}$, as well as the narrator's and her aunt's endorsement of an overtly Pakeha lifestyle and perspective, seem to point to a culture in perdition, threatened perhaps by the growth of the tourist industry. Indeed, during her peregrinations in and around Picton, the narrator cannot help noticing that "there were people everywhere" (6). Although she admits that days out picnicking in the Sounds must be tremendous, "especially for the kiddies" (5), with races, free lollies and "the Maori singing and playing their ukuleles" (5), she nonetheless notices that the latter "didn't sing the real Maori songs, they sang You are my sunshine and South of the Border" (5). The young woman's unease towards the new Picton possibly betrays a hushed hostility towards the Pakehas' meddling with the land and, above all, to the spectacle of a culture on its knees, gnawed at as it is from the inside by its own assimilation of foreign references. I would like to argue here that "The Lagoon" alludes to the collision of Maori and Pakeha cultures which, in so far as it entails no genuine reciprocity whatsoever, falls short of a true cross-cultural encounter. Expressing her concern with the issue of cultural absorption, Frame stresses in one of her rare essays that: 
countries high in literacy and publishing opportunities, reinforced by an abundance of exported films, can almost vacuum-clean, overnight, another culture and language. This has happened chiefly with the use of media which do not require a high degree of literacy - pop-music, film, television. ("Departures and Returns" 92)

In "The Lagoon", then, Frame already raises the issue of "New Zealand's vulnerability to encroaching American consumerism" (Wilson 118), to which she will return at the end of her career.

The connection between the "vacuum cleaning" ("Departures and Returns" 92) of the Maori culture and the women's hesitation in "The Lagoon" to transmit their narratives requires further delineation. I have suggested that, as a child, the narrator sensed that there was more to the lagoon than her grandmother was prepared to let on:

See the lagoon, my grandmother would say. The dirty lagoon, full of drifting wood and seaweed and crab's claws. It is dirty and sandy and smelly in summer. I remember we used to skim round white stones over the water [...] and make sand castles on the edge. This is my castle we said, you be Father I'll be Mother and we'll live here and catch crabs and tiddlers for ever. (3-4)

Perusing a photograph of her great-grandmother, "the Maori princess with her big brown eyes, and her lace dress on" (6), the young woman intuits yet again the relevance of the lagoon as a backdrop to the family history; she therefore reiterates her wish for the veil of secrecy to be lifted. So far her aunt, much in her own mother's fashion, had merely echoed the statement that "at low tide there is no lagoon. Only a stretch of dirty gray sand shaded with dark pools of sea water" (3), but now she divulges at last that the young woman's greatgrandmother murdered her husband, drowning him in the lagoon. Instinctively, the grandmother and aunt had diverted attention from the murder out of a sense that it is:

The sort of story they put in Truth, [the aunt] said. On the morning of the tragedy witness saw defendant etc. etc. Your great-grandmother was a murderess. She drowned her husband, pushed him in the lagoon. I suppose the tide was high, I don't know. They would call it "The Woman from Nelson," she mused. They 
would have photos. But then nobody knew, only the family. Everybody thought he had had one over the eight and didn't know where he was going. (6-7)

Clearly, the story never made the front page of Truth as it was taken for granted that the greatgrandmother's husband simply sneaked away from his wife. Frame's contempt for newspapers, let alone for scandal tabloids such as the New Zealand Truth, is not new; it expresses her preoccupation with the realities that mimetic or journalistic writing tends to occlude (see Delrez, Manifold Utopia 163). For her, any sanctification of the past in its official version amounts to an outrageous effort at simplification, where competing or diverging memories of an event are necessarily overshadowed in favour of the preferred truth. It is no coincidence, then, that the kind of writing which is an act of deception should be epitomized in a tabloid called Truth.

When the aunt in "The Lagoon" exclaims that she prefers "Dostoevsky to Truth" (7), she implies that, should ancestral memories emerge from the lagoon, art only (love songs for instance) would constitute a viable means of exploration; far more so than a newspaper in which the past is first appropriated and manipulated or "seized and reshaped" for the sake of sensation, to be disposed of as soon as the news becomes stale. This incidentally points to the nature and role of the lagoon. It is, of course, one of these vast expanses of water which, in Frame's work, typically houses our repressed history and various eclipsed layers of existence; "and the losses are secret and no one ever learns the extent of them" (Human Heart 80). Yet, because a lagoon only exists at times, the losses usually buried deep in seas or lakes or reservoirs are apt to resurface at low tide. Therefore, the lagoon symbolizes in Frame's waterscapes all that which can be lost and subsequently retrieved, albeit only through memory.

Insofar as it presumably feeds on juicy scandals regardless of their social or ethnic origins the newspaper Truth, it can be assumed, is fairly unprejudiced in its erasure of the past. Yet the notion of cultural appropriation returns through the back door of the tale in the form of the ethnic affiliations of those who harbour no memory of the Maori princess and to whom her narrative has nevertheless been transmitted. Despite the aunt's claim that the secret was carefully kept within the family, one gets a sense that it nevertheless percolated into Picton's Maori community at large. Perhaps the notion of family should be understood to encompass not only the great-grandmother's relatives but also the rest of her community. In any case, it is no coincidence that the love songs which the Maori intone in Frame's 20thcentury New Zealand should echo their earlier princess's story. The Maori, therefore, can be 
said to heed the aunt's statement that Dostoevsky is preferable to Truth since they explore the past through art. Jimmy Kennedy and Michael Carr's "South of the Border" harps on a womanizer and his unfulfilled promise to love a woman who caught his eye at a fiesta as she was clad "in old Spanish lace":

She smiled as she whispered mañana

Never dreaming that we were parting

Then I lied as a whispered mañana

Cause our tomorrow never came (see <www.songlyrics.com $>$ )

Likewise, Jimmie Davis and Charles Mitchell's "You Are My Sunshine" evokes again a story of unbounded love and the warning issued by the singer that: "If you leave me / To love another / You'll regret it someday" (see <www.netstate.com>). Eventually, the loved one does leave the singer for another, but whether s/he is drowned in Toledo Bend Lake (Louisiana) is not mentioned in the text. Interestingly, "South of the Border", the song which parallels most substantially the official version of the husband's disappearance, embraces a masculine viewpoint, whereas "You Are My Sunshine", the song which resonates with the family's secret, appears to stem directly from the great-grandmother's consciousness. In other words, although the inclusion of the two competing versions may seem strange at first, the point is that in giving pride of place to official - that is masculine and white - and to non-official that is feminine or Maori - histories, the Maori singers commemorate the past in its fullest sense. Thus, when the Maori code their memories for fear that these should be distorted by a scandal tabloid, they also counter the integration of their past into a dominant narrative which tends to retain only one reshaped version of the past. The paradox is that the foreign repertoire on which they draw to chant the past can be regarded ambivalently as a token of their mental colonization and as a strategy for deflecting neo-colonial schemes. As we shall see, this indeterminacy is of crucial importance when it comes to determining the politics not only of "The Lagoon" but also of The Carpathians, for it makes it clear that the Maori cannot be dismissed as inauthentic by virtue of the fact that they find their inspiration in European or American cultures.

Interestingly, the popular love songs which the Maori make use of as a code understandable only to those who know the secret find a counterpart in the litany recited by the Maori princess's descendants. The ultimate repetition (with slight variations) of the story's opening sentence has been interpreted in terms of resolution, as carrying a suggestion that "a 
family taint is concealed as the story ends with a return to the childhood images of sandcastles and fishing" (Evans 40). In my view, however, the emphasis on the children saying "this is my castle, $[. .$.$] you be Father and I'll be Mother and we'll live here and catch crabs and tiddlers$ for ever" (7) in fact betokens another, though covert, acknowledgement of the murder. On the point of absconding with the woman from Nelson, the husband was brought back to earth, or rather pulled under water, by his wife. Thus immobilized in life, he indeed remains in the lagoon "catching crabs and tiddlers for ever", and Father and Mother were never separated at least not geographically speaking. The ultimate repetition of the litany, therefore, should be read as a sign that the memory of the Maori princess will continue to be commemorated in its coded rather than its factual version. Again, this strategy is a preemptive strike aimed at safeguarding the past against any appropriating drive.

In another sense, this reading further suggests that the spiritual void which disorients the young narrator upon her arrival in Picton may not be as absolute as it first appears. Indeed, the culture supposedly on its knees because of its colonization by eurocentric references is in fact still very much alive and resisting neo-colonial endeavours. The same is also true within the narrator's family, given that they exhibit an organic attachment to the past, which they transmit from one generation to the next. We shall see in further detail how the void, a recurring motive in Frame and a possible manifestation of "dissolution", is sometimes mistakenly conceived of as an empty darkness while in fact it is traversed by creative undercurrents and tides. On account of the negative value ascribed to the void, individuals and cultures constructed around "a dark still centre" tend to be indicted as inauthentic. This has led to misconceptions of Frame's apparently peculiar interest in the Maori (for example by Ingram or Williams). For the time being, however, suffice it to say that repressing the need to salvage the past for fear of being dispossessed of it is not a viable prospect, because under such conditions the past fails to endure and falls into oblivion. In coding their memories, the Maori in "The Lagoon" have then opted for yet another alternative, by dint of which they arguably succeed in moving beyond this dilemma or cultural blockage. Whether the Maori's taste for secrecy, fostered by a legitimate anxiety about the transmission of their past, is reconcilable with the dominant culture's yearning to revise its narratives in the light of Maori myths and legends, is an issue which must be addressed in view of Frame's poetics of dissolution.

It is of crucial importance that, as the narrator quotes her family's litany at the close of "The Lagoon", she is unable to determine from whose consciousness it has originated: "Was it my aunt speaking or was it my grandmother or my great-grandmother who loved a white lace dress?" (7). The continuity between the four generations of women is so strong that at times 
their identities intermingle. However much the Maori legacy has been diluted within the family, the dissolution of individual barriers that is foregrounded in "The Lagoon" shows that the connection between the Maori princess and her descendants is more enduring than what the text ostensibly implies. This also justifies the opposition that has been drawn in this essay between the dominant masculine culture and a family characterized by its female protagonists as well as by a Maori heritage which was lost and then retrieved as the four women formed one continuum of beings. Oblique though it may be, the existence of a continuum of identities in "The Lagoon" is a hint that the interpenetration of selves runs counter to the expansion of the ego. The women suspending their belief in self to transmit a memory in "The Lagoon" is crucial because, should they fail to do so, each woman would seize the memory from the previous generation in order to satisfy the appetite of the ruling ego. For a family so keen on safeguarding their history against whatever usurpers are lurking in the background, such egotism would turn them into accomplices of a system they seek to dismantle.

It is hardly surprising that in A State of Siege, a pivotal text in its function as a hyphen between cultural and interpersonal dispossessions, the link between strategies of exclusion and of appropriation should once more appear. The "national claim for identity" (Frame, State of Siege 124) is very concretely implemented by some Pakeha who

were now trying to falsify genealogical tables so that they might be able to trace an obscure relative who was a Maori! [...] Malfred was reminded, by this national claim for identity, of the phase that children experience when discovering that they are separate beings; they disown their parents and dream themselves into the exciting newness, individuality, uncertainty, of having been "adopted". (124-25)

Disowning one's relatives, as well as discarding some versions of the past in favour of a single sanctified truth, are necessarily contingent on the deployment of strategies of exclusion. Williams aptly explains in Leaving the Highway that, to "assert a special national character" (12), the Pakeha have tended to try and purge the national self-definition of its European component - and concomitantly they also evacuate "the history of the colonial encounter" (12) - to retain only the indigenous features of the country. This urge, he goes on, is regrettable, for it serves "the purposes of an ancient but psychologically devious need among the descendants of the settlers to validate their appropriation of the original inhabitants' land by a further act of appropriation" (13). Thus, although appropriation and exclusion appear 
very much as antithetical directions, both attest to neo-colonial manoeuvres, and, in that sense, these binary opposites are unidirectional.

The same dynamic of exclusion also underpins the endeavour to protect one's integrity against any symbolic appropriation by cladding the self in an armour equipped with "specially fitted claws and stings" (Frame, Human Heart 84). Malfred in A State of Siege tries to "arm [herself] with a New View, a New Life" (180). Miss Abson's hands in "An Incident in MidOcean" have become "gnarled with digging moats and destroying bridges", for she finds it "necessary always to build tall fires around her camp to ward off the beasts of prey which nevertheless [surround] her" (Frame, Reservoir 108). Examples of individuals creeping behind metaphorical fortresses the better to guard their territories against potential or imagined trespassers, in what amounts to yet another strategy of exclusion, are countless. Yet, although each individual is a fortress, no man is an island in Frame's work for, no matter what kind of ramparts, moats or camp fires the self calls upon to keep the beasts of prey at bay, in the end it is invaded. ${ }^{1}$ As they realize how spurious their protection is and how isolated a fortified self can be from any chorus of beings, some characters, like the narrator in "Prizes", Malfred's father in A State of Siege or Dinny Wheatstone in The Carpathians, decide to "discard all the known means of defence and retaliation" (Frame, Human Heart 84). This amounts to saying that they allow their selves to overlap with other identities or that they submit to "amputations of [themselves]" (Frame, State of Siege 189). One understands, therefore, why Malfred at some point exclaims that: "there is nothing I grasp of [my father] that does not belong to another person, age or place" (186) or why Dinny "inhabits all worlds except the world of [her] self (Frame, Carpathians 51). Forsaking the straitjacket of individuality is therefore either the price to pay or the reward to receive in accommodating otherness and, arguably, in parting with or hosting other people's essence: their feelings, dreams and successes, but also their memories. In other words, a reciprocal exchange occurs between individuals when an unarmed (i.e. permeable) self relinquishes a fragment of its essence, which another equally porous self then welcomes into the core of its being. $A$ contrario, the countless cannibal selves and shielded identities which resort to strategies of exclusion, either to stake their claims in other selves or to defend their integrity against intruders, cannot cross the "unfathomable darkness between man and man" (Frame, Reservoir 46) to come into contact with another heart. And, as we shall see, this precludes their becoming one with the "soul of New Zealand".

Frame's poetics of dissolution possibly sheds a new light on the much-discussed issue of the representation of the Maori in The Carpathians. Some critics, on the one hand, argue 
Published in Journal of Postcolonial Writing 46.2 (May 2010), pp. 209-220.

Status: Postprint (Author's version)

that the Maori are presented as essentially alienated from their own culture and language, which they have to reinvent as part of their own quest for collective identity. To Delrez and Williams, for instance, the main character's journey to the Maori marae is deeply unsettling, for

instead of finding the intact memory of spiritual presence as something healing and active, [Mattina] finds only a nagging sense of dislocation and a boy who, left thirty years in a mental hospital because nobody noticed and, released, now apparently contentedly making baskets [...] represents a Frameian might-havebeen. (Williams 53)

Such representation of Maori culture, in their view, prevents the temptation to appropriate Maori experience as a short-cut to any prefabricated national identity supposedly available for consumption by settler New Zealanders. Other critics, by contrast, argue that Mattina experiences a certain epiphany on the marae (Michell 122). Valerie Sutherland, for example, contends that the Maori have preserved and "exhibit an organic attachment to the land and to each other" (111), which she intuitively links with the tradition of flax weaving. The point is perhaps that the permeability entailed in flax weaving is akin to a state of dissolution; a successful flax weaver, Rua explains to Mattina, indeed

must know flax. I know flax and flax knows me. You understand the sort of knowing I mean? [...] Yes, you must have a special feeling about flax to be able to grow it, cut it without making it bleed, scrape it without hurting it, and weave it without going against its wishes. (Frame, Carpathians 86)

In other words, basket-weavers must respect the twin principles of non-violence and reciprocity, which, crucially, are also the requirements that Rua delineates as necessary for true cross-cultural, interpersonal or metaphysical encounters. In that sense, the boy "contentedly making baskets" may represent less "a Frameian might-have-been" (Williams 53) than a positive success so that the void which Williams and Delrez allude to is, exactly as in "The Lagoon", anything but non-creative. Thus, not only does the novel affirm the Maori understanding of the land but also their superiority in that their knowledge of flax weaving remains unsurpassed by the Pakeha. 
To pursue further the point that the Maori have retained a claim to authenticity, this is of utmost importance to the politics of The Carpathians, because it invalidates some of the charges which have been levelled against the novel as, for example, "enabl[ing] Decima's silence to appropriate the absent referent of indigenous presence" (Ingram 102). Indeed, despite the positive value ascribed to the reciprocal exchange lying at the root of "knowing and being known", Penelope Ingram misguidedly insists that "being known" must be construed negatively in terms of mental colonization, referring to "those natives of Puamahara who have been colonized, who have been known". As Decima is "brand new" and "cannot be known", Ingram claims, she is "uncolonizable" (99) and, therefore, authentic, and she concludes that, "thanks to the textual genocide" perpetrated in the novel, Decima is erected "in place of the indigene" (94). This argument, however, ignores the fact that the permeability entailed in "knowing and being known", "being accommodated by and accommodating", being "possessed by and possess[ing]" (Frame, Carpathians 16), conditions the reciprocity or non-violence of the exchange between an individual and other beings or even nature for that matter. Despite the numerous implications of this philosophy, it is enough that Dinny Wheatstone's "inhabit[ing] all worlds except the world of [her]self" (51) is less a token of her ostensible mental colonization than a suggestion that she has actually forsaken her own ego; as she says, an "Official Imposter" such as herself "never develops a self" (44). Having discarded the ego which excludes, Dinny's self becomes a void of sorts which resonates like a "cathedral" (16-17) with other beings. This probably explains why she displays an organic knowledge of the people she encounters; as she explains: "I get [this knowledge] from the air - yet it comes from the core of [myself] as I'm not cluttered up with my own being" (44). And, although Dinny remains unknown to most other selves, arguably because people content themselves with a kind of knowledge which is superficial, often a mere appropriation, it nevertheless remains the case that she is "known" by the remainder of the world. Indeed, those who

have no home may not ally their being to a house or gate or an item or furniture or adornment [used to anchor the human identity] but they are possessed by and possess those other forces or presences that also are homeless - the sky, the wind, the elements. (Frame, Carpathians 16-17) 
The point here is that, in dismissing the Maori's and Dinny Wheatstone's special brand of knowledge on account of the fact that they are "known", Ingram paradoxically implements the textual genocide she accuses The Carpathians of committing.

By way of conclusion, I would like once again to curve time and emphasize the continuity of concern linking "The Lagoon" to The Carpathians - though the two texts were published nearly 40 years apart. Although Janet Frame often dwells on the vulnerability of the Maori language and culture, she can be credited with refusing to become complicit with the neo-colonial endeavour, that is, by denying the indigenes any claim to origins on account of the fact that they have been influenced by Eurocentric values. Indeed, relegating authentic indigenes to a pre-European, uncontaminated, past amounts to creating a terra nullius, which the very perpetrators of such contamination can too easily recuperate and re-articulate with reference to non-indigenous settlers. In "The Lagoon", US popular culture, conveyed in the English language, is certainly an instrument of mental colonization of the Maori. In a further twist, however, language as the epitome of white hegemony is in turn instrumentalized as a means of resistance against the settlers' appropriating ethos. It is my impression that the ambivalence in Frame's texts between submitting to and resisting mental colonization complicates or makes downright illegitimate any attempts at discarding contemporary Maori voices as inauthentic. Thus, even though the Maori heritage has become diluted in "The Lagoon" and in The Carpathians, the point is perhaps that, in failing to regard the Maori staged in both texts as authentic, one clears the space for further colonization.

This essay has aimed to demonstrate that authenticity in Frame should not be equated per se with the absence of contamination. On the contrary, she favours a certain existential permeability for its illuminating capacity to alter the flawed protocols of cultural and metaphorical appropriation and pave the way for genuine cross-cultural, interpersonal and metaphysical encounters. Herein lies the raison d'être of Frame's poetics of dissolution, whereby our parasitical identity or ruling ego which excludes, is discarded while the void it unveils is shown to resonate with the remainder of the world. As we have seen, such a resonance is present amongst the four generations of women in "The Lagoon" and in the flaxweaving Maori in The Carpathians. It is interesting to note in this respect that flax-weaving in Maori culture is an activity which is traditionally allotted to women: "only women prepared flax for weaving - gathering leaves of the plant, stripping out the fibres, softening and colouring them - and wove it" (King 86). Therefore, in reinstating the Maori special relationship with the land through flax-growing and -weaving, Frame initiates a revalidation of the feminine. This consideration demands a retrospective focus if related to "The Lagoon" 
in that the dissolution of individual barriers or overlapping of selves, itself concomitant with the transmission of ancestral memories, is experienced exclusively by the female members of the family. This is not to say that women are unencumbered by any ego or that men are incapable of intimations of non-violence, but that the locus of dissolution is situated outside masculine conquistadorial spheres.

If Dinny Wheatstone is a living (paper) proof that the core of human identity is possibly a void, the very existence of a white selfless character naturally testifies to the possibility for white settlers to become attuned to the world and, incidentally, to "the soul of New Zealand" in place of the Maori. One cannot help in this context thinking of Lettice Bradley, whose painting of a Maori legend awes her teacher, Malfred, for it shows that Lettice "'knew' the legend, with the biblical force of the work 'knew'" (Frame, State of Siege 122). Green with envy, Malfred wonders how Lettice "found her way to the secret store" and what places she "visited in her dreams that she [has] been apprehended by the soul of her own country" (122). Clearly, the girl is a white indigene of sorts and this suggests that, under certain conditions, it is possible for non-indigenous settlers to be "apprehended by the soul of their country". For one thing, however, the Framean texts sustain a sense in which permeability is indistinguishable from selflessness so that both states are synonymous with a way of being in the world that has dismantled all boundaries. In keeping with this, selfdissolution is more often than not depicted as an excruciating process where one's spiritual and/or physical integrity must be risked. As a result, few characters are willing to take the dreaded leap into the void. And, even were they to do so, their new at-oneness would constitute no threat to the Maori, for the ego which expands by devouring "enemies" would no longer exist. In other words, the dissolution of the ruling self makes any attempt at assimilation impossible, and lays the foundations for a multicultural society in its most utopian sense.

\section{Note}

1. This is evoked not only in "Prizes" but also in, for example, "The Window", "The Chosen Image" in The Reservoir or in "On the Car" and "A Note on the Russian War" in The Lagoon.

\section{Notes on contributor}

Cindy Gabrielle is a doctoral student in the Department of English and American Literatures at the University of Liège, Belgium. Her research interests include Janet Frame, postcolonialism as well as neo-colonialism and representations of cross-cultural encounters in 
literature. Her $\mathrm{PhD}$ dissertation examines Janet Frame's shorter fiction with a view to unravelling the complexities of an entire aspect of her work which, so far, has failed to receive the critical attention that it deserves.

\section{Works cited}

Ashcroft, Bill, Gareth Griffiths, and Helen Tiffin. The Empire Writes Back: Theory and Practice in Post-Colonial Literatures. London: Routledge, 1989.

Davis, Jimmie, and Charles Mitchell. "You Are My Sunshine." Peer International Corporation, 1940. Web. 1 February $2010<$ http://www.netstate.com/states/symb/song /la_you_are_my_sunshine.htm>.

Delrez, Marc. "Forbidding Bodies: Avatars of the Physical in the Works of Janet Frame." World Literature Written in English 38.2 (2000): 70-79.

- Manifold Utopia: The Novels of Janet Frame. Amsterdam and New York: Rodopi, 2002.

Drichel, Simone. '"Signposts to a World that is Not Even Mentioned': Janet Frame's Ethical Transcendence." Frameworks: Contemporary Criticism on Janet Frame. Ed. Jan Cronin and Simone Drichel. Amsterdam and New York: Rodopi, 2009. 181-212.

Evans, Patrick. Janet Frame. Boston: Twayne, 1977.

Frame, Janet. The Carpathians. New York: Braziller, 1988.

—. "Departures and Returns." Writers in East-West Encounters: New Cultural Bearings. Ed. Guy Amirthanayagam. London and Basingstoke: Macmillan, 1982. 85-94.

—. Faces in the Water. 1961. London: Virago, 2009.

—. The Lagoon and Other Stories. 1951. London: Bloomsbury, 1997.

—. The Reservoir and Other Stories. 1963. New York: Braziller, 1993.

- A State of Siege. 1966. New York: Braziller, 1980.

—. You Are Now Entering the Human Heart. 1983. London: Women's Press, 1984.

Goldie, Terry. Fear and Temptation: The Image of the Indigene in Canadian, Australian, and New Zealand Literature. Montreal-Kingston: McGill-Queen's UP, 1989.

Ingram, Penelope. "Can the Settler Speak? Appropriating Subaltern Silence in Janet Frame's The Carpathians." Cultural Critique 41 (1999): 79-107.

Jennings, Olivia. "Seeking Indigeneity: The Search for the 'Lost Tribe' in Janet Frame's The Edge of the Alphabet." World Literature Written in English 38.2 (2000): 80-93. 
Published in Journal of Postcolonial Writing 46.2 (May 2010), pp. 209-220.

Status: Postprint (Author's version)

Kennedy, Jimmy, and Michael Carr. "South of the Border Down Mexico Way." Music for South of the Border, a film by George Sherman, 1939. Web. 1 February 2010 $<$ http://www.songlyrics.com/frank-sinatra/south-of-the-border-down-mexico-waylyrics/>.

King, Michael. The Penguin History of New Zealand. Auckland and London: Penguin, 2002.

Michell, Isabel. "'Turning the Stone of Being': Janet Frame's Migrant Poetic." Frameworks: Contemporary Criticism on Janet Frame. Ed. Jan Cronin and Simone Drichel. Amsterdam and New York: Rodopi, 2009. 107-34.

Sutherland, Valerie. "A Ventriloquist in the House of Replicas: A Reading of The Carpathians." Journal of New Zealand Literature 11 (1993): 106-13.

Williams, Mark. Leaving the Highway: Six Contemporary New Zealand Novelists. Auckland: Auckland UP, 1990.

Wilson, Janet. "Post-Modernism or Post Colonialism? Fictive Strategies in Living in the Maniototo and The Carpathians." Journal of New Zealand Literature 11 (1993): 11431. 